\title{
Occupational causes of disorders in the upper limb
}

\author{
N J Barton, G Hooper, J Noble, W M Steel
}

The Industrial Injuries Advisory Council, an independent statutory body, recently invited the British Orthopaedic Association to advise whether there was conclusive evidence of an occupational cause of any further types of repetitive strain injuries other than those currently recognised as industrial injuries. Two related conditions are currently recognised as "prescribed disorders": PD A4-cramp of the hand or forearm, in people with an occupation entailing prolonged periods of handwriting, typing, or other repetitive movements of the fingers, hand, or arm; and PD A8-traumatic inflammation of the tendons of the hand or forearm or the associated tendon sheaths in any occupation entailing manual labour or frequent or repeated movements of the hand or wrist. A group of surgeons with a major interest in conditions of the hand and upper limb was asked to study the topic on the basis of their clinical experience and a review of the literature. Our report appears below.

\section{Recent studies}

Two large studies were recently commissioned by the Health and Safety Executive from the universities of Edinburgh and Birmingham, and we were asked to comment on these.

The study from the Institute of Occupational Medicine in Edinburgh looked at 580 cases of upper limb soft tissue disorders and compared them with 996 controls, who were orthopaedic patients without upper limb problems.' ${ }^{1}$ The most common conditions were the carpal tunnel syndrome and ganglia, both of which are known to be more common in women. The occupations found to be overrepresented included cleaner, hairdresser, visual display unit and keyboard operator, and music teacher. These are jobs commonly done by women. In all, $70 \%$ of the cases in the study were women, compared with $36 \%$ of controls, so that case and control groups were not matched. The report made no attempt to study the relations of particular conditions to occupations.

The study from the School of Manufacturing and Mechanical Engineering in Birmingham approached the problem from the other end: the place of work. ${ }^{2}$ Workers with self reported upper limb disorders from 14 industrial sites, representing nine industries, were matched with asymptomatic people doing the same job (non-cases).

The 188 page report described 100 "matched pairs," who were examined by a research physiotherapist. The site and nature of repetitive strain injury was reported as thoracic neck joint dysfunction in $48 \%$ of cases, as wrist joint dysfunction in $29 \%$, wrist tendonitis or tenosynovitis in $21 \%$, and shoulder joint dysfunction in $17 \%$. The diagnostic criteria were not strictly defined.

The authors themselves concluded that their survey could not provide reliable data on incidence or prevalence. Furthermore, no comparison was made between the assessments of the workers and of controls from the normal population. The unsubstantiated assumption was made that because a symptom was present it was the work which had caused it. Repeated reference was made to "injury." The diagnostic criteria used by the

\section{Misleading terms}

Repetitive strain injury (RSI) implies the existence of a physical condition with an identifiable cause. The physical signs (if present) are imprecise and there are virtually no data on any pathological lesions. Hadler, who has done much to investigate this group of disorders, states that dystrophic or inflammatory change have seldom if ever been described. ${ }^{3}$

The word strain is not used in its true mechanical sense but in a lay sense.

An injury is a single event, implying violation of a "victim" and thus culpability on the part of an employer and potential for litigation.

Tenosynovitis is a clear cut entity, in which the synovium around a tendon becomes inflamed. Strangely the term is often applied to conditions in which there is no synovium. Semple believes that in most legal cases the initial seed is sown when the patient has an initial vague ache in the hand or forearm. ${ }^{+}$Often before any diagnostic signs are present the factory doctor or general practitioner writes "tenosynovitis" on the sick note. This initial misdiagnosis of tenosynovitis is the most frequent source of misunderstanding ${ }^{5}$ and may start the patient on the course towards litigation.

research physiotherapist of wrist, shoulder, or thoracic or neck "dysfunction" were open to question. Most of the symptoms could have been due to well established degenerative conditions of the neck and upper limbs such as cervical spondylosis, rotator cuff lesions, epicondylitis, or arthritis of the wrist and hand.

We concluded that it was disappointing that after so great an expenditure of time and money so few conclusions could be drawn from these two studies.

\section{Work and recognised syndromes}

We reviewed a variety of well recognised (and recognisable) conditions to see what evidence there is that these are work related. The box gives the meaning of some terms that are used throughout the report that may be misleading.

\section{NECK DISORDERS}

In 1969 Laurence affirmed that at any time a tenth of the population has pain in the neck or arm, or both, and that a third would at some stage of their lives be thus afflicted. ${ }^{6}$ Radiographs are of little help. By the age of $65,90 \%$ of the population have radiological evidence of cervical spondylosis. It would be fair to say, however, that in certain occupations such as typing the head is often held in an awkward position, which could predispose to symptoms from the degenerative changes. ${ }^{7}$ (In 1988 the title of an editorial by Smythe suggested that "'repetitive strain injury syndrome' is referred pain from the neck."

\section{THE THORACIC OUTLET SYNDROME}

In a recent review Cuetter and Bartoszek estimated the true incidence of the thoracic outlet syndrome, which is caused by nerve compression in the root of the neck by anatomically abnormal structures, as one in a million. ${ }^{9}$ They pointed out that in the so called

Mr Barton.

BMF 1992;304:309-11 
non-specific thoracic outlet compression syndrome there are no objective signs and no identifiable anatomical abnormalities. As this condition is by definition due to a rare anatomical abnormality, it cannot be caused by any type of work and the use of the term the thoracic outlet syndrome for non-specific upper limb discomfort not associated with objective physical signs should be condemned.

\section{SHOULDER DISORDERS}

Frozen shoulder-Our review found no connection between frozen shoulder and occupation. Indeed, Neviaser found adhesive capsulitis and painful stiff shoulder to be commoner on the left side than on the right and more common in sedentary workers than in labourers. ${ }^{10}$

The impingement syndrome, also known as the painful arc syndrome or rotator cuff syndrome, is - according to Hawkins and Abrams - something to which "individuals who use their arms above the horizontal are especially at risk." avascular area in the supraspinatus tendon, which Rathbun and McNab showed was affected by position of the shoulder. ${ }^{12}$ However, what is starkly lacking from the literature is any hard evidence of proved rotator cuff lesions being more common in certain occupations. Hawkins and Kennedy did show that the impingement syndrome was common in sportsmen who used high overhead actions, such as swimmers. ${ }^{13}$ Theoretically what could happen in sport can occur at work. We believe that while there is no strong evidence of occupationally caused shoulder disorders, the circumstantial evidence is enough to make the possible association worthy of further study.

\section{ELBOW DISORDERS}

Chard and Hazelman in their recent review of tennis elbow (lateral epicondylitis) reported that it affects $1-3 \%$ of the population, commonly between the ages of 40 and $60 .{ }^{14}$ The sex ratio is equal. The lesion usually affects the dominant arm, and most patients are not manual workers (or tennis players). The nature of the pathological lesion is obscure. Goldie regarded overexertion as a definite factor causing epicondylitis. ${ }^{15}$ However, Hamilton found an incidence of four cases of humeral epicondylitis per 1000 patients in a general practice without a preponderance of manual workers. ${ }^{16}$ Luopajarvi et al compared shop assistants with assembly line workers in a food product factory and found tennis elbow to be commoner in the assembly workers, ${ }^{17}$ but Viikari-Juntura concluded that there was no scientific proof that movements such as repetitive dorsiflexion of the wrist and prosupinations of the forearm cause the tennis elbow syndrome. ${ }^{18}$ Dimberg surveyed workers in the Volvo Aircraft Engine Division and found $7 \cdot 4 \%$ to have tennis elbow, which was equally common among white collar and manual workers. ${ }^{19}$

While the cause and nature of tennis elbow are still subjects for speculation there is good evidence that it is not commoner among manual workers and is not clearly associated with any particular working activity. When it does occur, however, it is likely to be more troublesome in those with manual work.

\section{WRIST AND HAND LESIONS}

Peritendinitis crepitans is a clear cut condition with pain, swelling, and crepitus in which the thumb extensors cross the radial wrist extensors. Its association with rapid repeated movements at the wrist was shown in 1951 by Thompson et al at the Vauxhall car factory. ${ }^{20}$ This disorder may be caused by work and is already a prescribed condition (PD A8, formerly PD 34).

De Quervain's stenosing tenovaginitis is characterised by thickening of the fibrous sheath or retinaculum, though there may also be some synovial sheath inflammation. Leao considered it to be occupationally related in some cases, ${ }^{21}$ and we believe that where this is demonstrably so then those instances may be placed under the existing classification PD A8. In our experience, however, De Quervain's disease is rarely caused by occupation.

Trigger digit-McFarland thought that trigger digit might be common in long distance drivers or those with repetitive tasks, but the evidence for this claim remains obscure. ${ }^{22}$ For example, Kivi published a review of 3090 reports of rheumatic disorders of the upper limbs associated with repetitive occupational tasks in Finland in 1975-9. There was no evidence of trigger finger arising from occupational causes. ${ }^{23}$

The carpal tunnel syndrome-Histopathological examination of tenosynovium removed at operation for the carpal tunnel syndrome has shown a striking absence of inflammation. ${ }^{24}$ The evidence regarding an association with occupation is mixed. Feldman et al found the syndrome to be commoner in those with rapid repetitive jobs in an electronics factory..$^{25}$ Birkbeck and Beer found it to be common among boot and shoe workers in Northampton. ${ }^{26}$ They admit their lack of control data, and this lack applies to most studies of the carpal tunnel syndrome. Nathan et al carried out nerve conduction studies in 471 employees from 27 occupations in four factories. ${ }^{27}$ No consistent association was found between the type and the level of occupational hand activity and the prevalence or severity of unpaired sensory conduction. They commented that "If occupational hand activities were a major risk factor associated with impaired sensory conduction we would expect that the longer one had worked in an industry the greater would be the risk of having impaired conduction. Our findings show that this is not the case." Hadler concluded that the carpal tunnel syndrome was probably not more prevalent in any industry nor caused by any type of work. ${ }^{3}$ We think there may be a few cases in which a certain activity at work has brought on symptoms of the syndrome, but that the vast majority of cases are not caused by work. If the disorder is already present then certain tasks may exacerbate it.

The cubital tunnel syndrome is much rarer than the carpal tunnel syndrome and usually has an anatomical basis or pathological basis, or both. Salan et al recently described this lesion in three heavy goods vehicle drivers who rested their right elbows on the driver's window ledge. ${ }^{28}$ But this simply shows that direct pressure on the ulnar nerve causes symptoms in its distribution; it is scant evidence for a work related disorder.

Ganglions-Barnes et al studied 257 patients with ganglions of the hand and wrist and concluded that "occupation seems to have no bearing on their presence or absence." ${ }^{29}$ In a recent review Hooper found no indication that wrist ganglions were caused by any type of occupational activity. ${ }^{30}$ However, the symptoms are likely to be worse in people undertaking repetitive movements.

Osteoarthritis at the base of the thumb is most prevalent among middle aged women. It is a little commoner on the non-dominant side, and the incidence among employed women is similar to that in housewives. There is no evidence for a work related aetiology, although again those with the lesion who do manual work will have more symptoms.

Dupuytren's contracture is so common that a quarter of all male pensioners show evidence of it. ${ }^{31}$ Inheritance, ${ }^{32}$ diabetes, ${ }^{33}$ epilepsy, ${ }^{34}$ and alcoholism ${ }^{35}$ are all accepted aetiological factors. With regard to occupation, the seminal study was that of Early in 1962, who examined the hands of 5000 workers at Crewe 
locomotive works. ${ }^{36}$ The incidence among heavy manual workers was similar to that among clerical workers. Similar findings were reported by Fisk, who compared members of the merchant marine. ${ }^{3}$ Hueston, however, considered that Dupuytren's disease may be exacerbated by a single injury or subsequent immobilisation in people with a preexisting predisposition to it. ${ }^{38}$ Fisk concluded that occupation and recurrent trauma has no effect on the incidence of the disease. ${ }^{37}$

\section{Non-specific arm pain (repetitive strain injury)}

The term repetitive strain injury has been widely used as a convenient, if inaccurate, collective term for occupational arm pain, although it has not been clearly defined clinically by recognisable signs and symptoms ${ }^{39}$ It has no identifiable pathological basis. ${ }^{40}$ In 1988 Fry reported changes in muscle biopsy specimens in the overuse syndrome: these might have been of significance but they were not compared with control specimens.

The characteristic pain in the arm in patients with repetitive strain injury does not conform to any identifiable anatomical or pathological pattern. Ireland attributed much of the malady to boredom in people with badly paid, monotonous jobs..$^{42}$ The employees clearly placed the blame on the employment and thus on the employer. However, Ireland reported that despite total avoidance of pain inducing activities many patients' symptoms continued to deteriorate and they culminated in litigation. ${ }^{42}$

The epidemiological data on repetitive strain injury are also unpromising. Laurence, studying Lancashire mill workers, found symptoms of the repetitive strain injury type to be slightly less common in those doing repetitive tasks at work than in those not. ${ }^{43}$ It was difficult to explain the incidence of $25 \%$ for symptoms of repetitive strain injury in telegraphists in Sydney doing the same job with the same equipment as their colleagues in Melbourne, in whom the incidence was $4 \% .^{++}$What is certain is that disability and claims are on the increase. ${ }^{2}$ Our review of an entire supplement to the Fournal of Hand Surgery devoted to occupational disorders of the upper extremity failed to come up with sound objective evidence for occupationally related repetitive strain injury. ${ }^{4}$

\section{Conclusions}

The terminology used in published work on repetitive strain injury is most unsatisfactory and should be discarded. No condition should be prescribed as an industrial disease unless it can be unambiguously defined both clinically and pathologically. At present there is insufficient conclusive evidence of occupational causation to prescribe any further types of "repetitive strain injuries." There may be some cases, however, coming to civil litigation in which on the balance of probabilities the condition may be ascribed to an occupation, though the evidence may not be conclusive.

Further research is required in the form of properly designed and controlled studies. Only with results from such studies can we truly address the problem of preventing disorders of this type from being caused in the workplace.

\footnotetext{
English CJ, Maclaren WM, Court-Brown C, Hughes SPF, Porter RW, Wallace WA, et al. Clinical epidemiological study of relations between upper Wimb soft tissue disorders and repetitive movements at work. Edinburgh: Institute of Occupational Medicine; 1989. (Report No 7M/88/19 UDC 616.74.)
}

2 Thompson D, Bacon PA, Harrington JM Nayak USL Occurrence and mechanism of occupational repetition strain injuries. Birmingham: School of Manufacturing and Mechanical Engineering, University of Birmingham, 1990

3 Hadler NM. Illness in the workplace: the challenge of musculo-skeletal symptoms. $\mathcal{F}$ Hand Surg [Am] 1985;10A:451-6.

4 Semple JC. "Tenosynovitis." 7 Hand Surg [Br] 1986;11B:155-6.

5 Jackson JP. Repetitive stress injury. In: Foy, MA, Fagg PS, eds. Medicolegal reporting in orthopaedic trauma. Edinburgh: Churchill Livingstone, 1990: $447-56$.

6 Laurence JS. Disc degeneration. Its frequency and relationship to symptoms. Ann Rheum Dis 1969;28:121-37.

7 Grandiean E. Postural problems at office work stations. In: Ergonomics and health in modern offices. London: Taylor and Francis, 1969:444-5.

8 Smythe $\mathrm{H}$. The "repetitive strain injury syndrome" is referred pain from the neck. I R heumatol 1988;15:1604-8.

9 Cuetter AC, Bartoszek DM. The thoracic outlet syndrome: controversies, overdiagnosis, overtreatment, and recommendations for management. Muscle and Nerve 1989;12:410

10 Neviaser JS. Adhesive capsulitis and the stiff and painful shoulder. Orthop Clin North Am 1980;11:327-31

11 Hawkins RJ, Abrams JC. Impingement syndrome in the absence of rotato cuff tear. Orthop Clin North Am 1987;18:373-82.

12 Rathbun JB, McNab I. The microvascular pattern of the rotator cuff f Bone foint Surg [Br] 1970;52B:540-4.

13 Hawkins RJ, Kennedy JS. The impingement syndrome in athletes. Am F Sports Med 1980;8:57-62.

14 Chard MD, Hazelman BL. Tennis elbow--a reappraisal. $\mathrm{Br} f$ Rheumato 1989;28: 186 .

15 Goldie I. Epicondylitis lateralis humeri. Acta Chir Scand 1964;suppl 339:

$1-119$.
16 Hamilton PG. The prevalence of humeral epicondylitis: a survey in general practice. $\mathcal{I} R$ Coll Gen Pract 1986;36:464.

17 Luopajarvi V, Kuorinka I, Virolainen A, Holmberg M. Prevalence of tenosynovitis and other injuries of the upper extremities in repetitive work. Scand $\mathcal{F}$ Work Environ Health 1979;5(suppl 3):48-55.

18 Viikari-Juntura E. Tenosynovitis, peritendonitis and the tennis elbow syndrome. Scand $\mathcal{f}$ Work Environ Health 1984;10:443-9.

19 Dimberg $L$. The prevalence and causation of tennis elbow (lateral humera epicondylitis) in a population of workers in an engineering industry. Ergonomics 1987;30:573.

20 Thompson AR, Plewes LW, Shaw EG. Peritendinitis crepitans and simple tenosynovitis: a clinical study of 544 cases in industry. $B r F$ Ind Med 1951;8:150-9.

21 Leao L. De Quervain's stenosing tenovaginitis. A clinical and anatomical study. F Bone foint Surg [Am] 1958;40A: 1063-70.

$22 \mathrm{McF}$ arland GB. Tendon entrapment syndrome. In: Evarts C McC, ed. Surgery of the musculoskeletal system. 2nd ed. New York: Churchill Livingstone, 1990:962.

23 Kivi P. Rheumatic disorders of the upper limbs associated with repetitive occupation tasks in Finland 1975-79. Scand f Rheumatol 1984;13:101-7.

24 Neal NC, McManners J, Stirling GA. Pathology of the flexor tendon sheath in the spontaneous carpal tunnel syndrome. F Hand Surg $[B r] 1987 ; 12 B$. 229-32.

25 Feldman RG, Travers PH, Chirico-Post J, Keyserling WM. Risk assessmen in electronic assembly workers: carpal tunnel syndrome. $\mathcal{F}$ Hand Sur [Am] 1987;12A:849-55.

26 Birkbeck MQ, Beer TC. Occupation in relation to the carpal tunnel syndrome. Rheumatology and Rehabilitation 1975;14:218-21.

27 Nathan PA, Meadows KD, Doyle L. Occupation as a risk factor for impaired sensory conduction of the median nerve at the carpal tunnel syndrome. $\mathcal{F}$ Hand Surg $[B r] 1988 ; 13 B: 167-70$

28 Salan A, Eyres KS, Cleary J. Drivers' (HGV) elbow: an unusual cause of ulnar neuropathy. $\mathcal{F}$ Hand Surg $[B r] 1991 ; 16: 436-7$.

29 Barnes WE, Larsen RD, Posch JL. Review of ganglion of the wrist and hand with an analysis of surgical technique. Plast Reconst Surg 1964;34:570.

30 Hooper G. Cystic swellings. In: Bogumill GP, Fleegler E, eds. Tumours of the wrist and hand. Edinburgh: Churchill Livingstone (in press).

31 James JIP. The genetic pattern of Dupuytren's disease and idiopathic epilepsy in Dupuytren's disease. In: Hueston JT, Tubiana RT, eds. Dupuytren's
in disease. (GEM monograph.) 2nd ed. Edinburgh: Churchill Livingstone, 1985:94-9.

32 Ling RSM. The genetic factor in Dupuytren's disease. F Bone foint Surg [Br] 1963;45B:709-12.

33 Noble J, Heathcote JG, Cohen H. Diabetes mellitus in the aetiology of Dupuytren's disease. F Bone foint Surg [Br] 1984;66B:322-5.

34 James JIP. The relationship of Dupuytren's contracture and epilepsy. The Hand 1969;1:47-9.

35 Noble J, Arafa MA, Royle SG, McGeorge D, Crank S. Dupuytren's, alcoholism and cirrhosis. 7 Hand $S u r g[B r]$ (in press).

36 Early PF. Population studies in Dupuytren's contracture. $f$ Bone foin Surg $[\mathrm{Br}] 1962 ; 44 \mathrm{~B}: 602-13$.

37 Fisk G. The relationship of manual labour and specific injury to Dupuytren's disease. In Hueston JT, Tubiana RT, eds. Dupuytren's disease. (GEM monograph.) 2nd ed. Edinburgh: Churchill Livingstone, 1985:104-5.

38 Hueston JT. In: Hueston JT, Tubiana RT, eds. Dupuytren's disease. (GEM monograph.) 2nd ed. Edinburgh: Churchill Livingstone, 1985:75-82. monograph.) 2nd ed. Edinburgh: Churchill Livin
Helal B. Tenosynovitis. $\mathcal{R}$ Soc Med 1987;80:68-9.

39 Helal B. Tenosynovitis. $\mathcal{F} R$ Soc Med 1987;80:68-9.
40 Ide CW. Again, again... repetitive strain. Rheumatology in Practice 1989: Ide CW. Again,
Oct/Nov 24-7.

41 Fry HJH. Over use syndrome of the upper limb in musicians. Med $\mathcal{f}$ Aus 1986;144: 182-5.

42 Ireland DCR. Psychological and physical aspects of occupational arm pain. $f$ Hand Surg $[\mathrm{Br}] 1988 ; 13 \mathrm{~B}: 5-9$.

43 Laurence JS. Rheumatism in cotton operatives. Br f Ind Med 1961;18:270-6. 44 Ferguson D. An Australian study of telegraphists cramp. Br f Ind Med 1971;28:280-5.

45 British Orthopaedic Association Working Party. Occupational disorders of the upper extremity. F Hand Surg $[A m]$ 1987;12A(suppl):821-970.

(Accepted 11 December 1991) 